\title{
Implementasi Perangkat Peremajaan dan Perawatan Alat Berat Container Crane
}

\author{
Wahibbullah, Derry Pramono Adi, Achmad Teguh Wibowo, MY Teguh Sulistyono, \\ dan Agustinus Bimo Gumelar
}

\begin{abstract}
The process of repair and maintenance planning on container cranes at the port is often considered ineffective due to a lack of management planning which influences the maintenance schedule. PELINDO III Surabaya Patchouli Terminal is a company engaged in loading and unloading container crane services. The loading and unloading process is determined by several factors, such as the number of containers and the weight of the cargo being managed, as well as the quality and quantity of equipment used. This continuous process affects the life of the container crane. Lack of precise determination of maintenance can have an impact on container crane performance. To answer this problem, planning is needed so that it is able to determine the right treatment time within a certain period of time. In this study, we implemented maintenance planning by implementing a web-based application using the PHP programming language and the MariaDB database. We use operational data at PT. BIMA PELINDO III Surabaya which includes scheduled production, scheduled maintenance, maintenance activities and scheduled forecasts. We determine the input variables based on operational data, followed by planning method modeling. Based on these input variables, the output variables will be obtained in the form of light and heavy clusters, with each class given a weighted prediction for container crane maintenance planning that is displayed to the application. The results of this maintenance planning application are expected to be able to determine the estimated maintenance activities, scheduled maintenance to run well, the use of fuel and other container crane operational resources to be more efficient.
\end{abstract}

Index Terms-Container Crane; Maintenance Application; MariaDB; PHP;

Wahibullah is with the Sistem Informasi,Fakultas Ilmu Komputer, Universitas Narotama, Surabaya, Indonesia (email wahibbullah@mhs.fasilkom.narotama.ac.id)

Via Ardianto Nugroho is with the Sistem Informasi, Fakultas Ilmu Komputer, Universitas Narotama, Surabaya, Indonesia (email: via.ardi@gmail.com).

Derry Pramono Adi is with the Sistem Informasi, Fakultas Ilmu Komputer, Universitas Narotama, Surabaya, Indonesia (e-mail: derryalbertus@ieee.org).

Achmad Teguh Wibowo is with the Fakultas Sains dan Teknologi, UIN Sunan Ampel, Surabaya, Indonesia (e-mail: atw@uinsby.ac.id).

MY Teguh Sulistyono is with the Fakultas Ilmu Komputer, Universitas Dian Nuswantoro, Semarang, Indonesia (e-mail: teguh.sulistyono@dsn.dinus.ac.id).

Agustinus Bimo Gumelar is with the Fakultas Ilmu Komputer, Universitas Narotama, Surabaya, Indonesia (corresponding author, email: bimogumelar@ieee.org)
Abstrak--Proses perbaikan dan perencanaan perawatan pada container crane yang di pelabuhan sering dianggap kurang efektif karena kurangnya perencanaan dalam pengelolaan yang berpengaruh dalam penentuan jadwal perawatan. Terminal Nilam PELINDO III Surabaya merupakan perusahaan yang bergerak dalam bidang jasa bongkar muat containercrane. Proses bongkar muat ditentukan oleh beberapa faktor, seperti banyaknya container dan berat muatan yang dikelola, maupun kualitas dan kuantitas alat yang digunakan. Proses secara terus-menerus tersebut mempengaruhi usia container crane. Kurang tepatnya penentuan perawatan bisa berdampak pada performa containercrane. Untuk menjawab permasalahan ini, dibutuhkan perencanaan sehingga mampu menentukan waktu perawatan yang tepat dalam kurun waktu tertentu. Pada penelitian ini, kami mengimplementasikan perencanaan perawatan dengan implementasi aplikasi berbasis web menggunakan bahasa pemrograman PHP dan database MariaDB. Kami menggunakan data operasional pada PT. BIMA PELINDO III Surabaya yang meliputi produksi terjadwal, penjagaan terjadwal, aktivitas pemeliharaan dan perkiraan terjadwal. Kami menentukan variabel input berdasarkan data operasional, yang dilanjutkan dengan permodelan metode perencanaan. Berdasarkan variabel input tersebut, akan diperoleh variabel output berupa kluster ringan dan berat, dengan setiap class diberi pembobotan prediksi perencanaan perawatan container crane yang ditampilkan ke aplikasi. Hasil dari aplikasi perencanaan perawatan ini diharapkan dapat menentukan perkiraan aktivitas pemeliharaan, perawatan terjadwal agar berjalan dengan baik, pemakaian bahan bakar dan sumber daya operasional container crane yang lain menjadi lebih efisien.

Kata Kunci- Aplikasi Perawatan; Container Crane; MariaDB; PHP;

\section{Pendahuluan}

aat ini, industri sedang mengalami apa yang oleh para ahli disebut "Revolusi Industri Keempat", juga disebut Industri 4.0[1]. Fakta ini sangat terkait dengan integrasi antara sistem fisik dan digital dari lingkungan produksi. Integrasi lingkungan ini memungkinkan pengumpulan sejumlah besar data yang dikumpulkan oleh peralatan yang berbeda, yang terletak di sektor yang berbeda dari pabrik[2].

Sektor yang berbeda seperti logistik dan pelabuhan, juga memerlukan integrasi antara aspek digital dengan kaitannya peralatan heavy load equipment. Di terminal 
peti kemas, panjang proses bongkar muat ditentukan oleh kualitas dan kuantitas alat. Namun karena minimnya manajemen resiko, kami mengimplementasi sebuah aplikasi untuk menentukan perencanaan perawatan yang sesuai untuk dilakukan pada container crane. Pembobotan perawatan berupa berat dan ringan yang mempunyai aktivitas berapa lama waktu perawatan terjadi pada setiap pembobotan. Di penelitian ini, kami menggunakan data operasional pada PT BIMA Surabaya. Kami menentukan variabel, yang selanjutnya akan dimodelkan dengan menggunakan metode $K$ Means Clustering. Hasil dari penelitian sebelumnya untuk mengetahui komparasi tingkat accuracy dari penerapan algoritma K-Means Clustering pada PT BIMA Surabaya, menunjukkan penelitian dengan menentukan titik pusat awal cluster yang akan diuji dalam bentuk kelas yang berbeda-beda.

\section{LANDASAN TEORI}

PHP merupakan bahasa pemrograman yang kerap digunakan untuk membangun aplikasi berbasis web[3], [4]. Novita dkk pada penelitiannya melaporkan keefektifan bahasa pemrograman PHP dalam merancang aplikasi penjadwalan [5]. Novita dkk merancang context diagram dan purwarupa antarmuka sistem, namun tidak menggunakan variabel dari studi kasus yang mempengaruhi dinamika penjadwalan. Tuaycharoen dkk juga merancang aplikasi yang mirip dengan Novita dkk [6]. Perbedaan diantara keduanya terletak pada studi kasus, namun masih pada instansi pendidikan. Tuaycharoen menggambarkan rancangan aplikasi miliknya menggunakan EntityRelationshipDiagram (ERD). Mirip dengan Novita, Tuaycharoen juga menggunakan database berbasis relational MySQL dan MariaDB tanpa menggunakan variabel yang dapat kemudian mempengaruhi penjadwalan tersebut.

Namun bukan tidak mungkin untuk menjadikan aplikasi penjadwalan menjadi sebuah aplikasi yang dinamis sesuai dengan variabelnya[7], [8]. Terlebih, kondisi lapangan yang tidak menentu mengukuhkan solusi berbasis web yang tidak statis. Shofyan dkk mengembangkan sebuah aplikasi penjadwalan yang mengarah kepada Sistem Pakar[9]. Dalam penelitian yang juga melibatkan rancangan purwarupa antarmuka sistem ini menggunakan metode ForwardChaining untuk penjadwalan dengan variabel mata pelajaran, kelas, hari, jam, ruangan, dan pengajar.

Untuk mendukung sistem penjadwalan yang dinamis, kami menggunakan $K$-Means Clustering. Kumar dkk meneliti pengaruh Ant Colony Optimization untuk pengembangan lebih lanjut dari K-Means Clustering. Objektif utamanya ialah untuk mencari jarak terpendek dari satu variabel yang memiliki lebih dari satu endpoint, yaitu Quality of Service[10]. Pada titik software, Muthusamy dkk menggunakan K-Means Clustering untuk penjadwalan pada sentra data mereka yang berbasis Virtual Machine (VM). Penelitian ini sering disebut dengan load balancing pada Cluster-based Task Scheduling (CBTS) [11]. CBTS ini adalah pengukuhan dari dasar penelitian yang dilakukan Lin dkk [12]. Pada penelitiannya, Lin dkk mengaplikasikan penjadwalan pada mesin-mesin terintegrasi pada sebuah pabrik. Pemahaman mesin-mesin yang saling berpengaruh pada satu sama lain ini mirip dengan yang terjadi kapal. Oleh karena itu, kami menggunakan K-Means Clustering yang umum digunakan untuk penjadwalan, serta yang dapat diaplikasikan pada kapal peti kemas[13].

\section{METODE PENELITIAN}

Kami menentukan variabel yang digunakan untuk kebutuhan penelitian agar memenuhi syarat metode yang digunakan. Data diambil dari PT. BIMA PELINDO 111 SURABAYA dari tahun 2019 sampai dengan 2020. Pengolahan data yang didapat oleh kami berupa data digital. Kepada pemberi data, kami sedikit berbincang untuk menanyakan masalah apa yang telah didapat saat memasukkan data secara manual sehingga kami bisa mengkaji data yang tidak dimengerti agar tidak terjadi pengambilan data yang redundan[14]. Data yang kurang lengkap akan dilewati untuk mempermudah analisa data mentah. Perawatan dan perbaikan pada sebagian data crane untuk dilakukan data traning dan data evaluasi untuk di kembangkan kembali pada setiap step data yang di uji coba menjadi data testing.

\section{A. Data Preprocessing}

Dalam tahap data pre-processing, kami bertujuan untuk memastikan data mana yang dapat diolah menjadi data mentah[15], lebih tepatnya memanipulasi data sebelum diinputkan ke dalam model data, yang ada pada report container crane. Penyebab utama dari data yang kurang baik untuk dijadikan model sesuai standar yang diinginkan[15], [16], antara lain: tidak lengkap, data pada kolom hilang, noisy, adanya data yang lain (random error). Juga hal-hal seperti inkonsistensi, tidak sesuai rule yang diinginkan, sehingga data menjadi tidak kompatibel dengan library yang digunakan. Contoh, tensorflow memerlukan inputtensor.

Data pre-processing yang baik dan benar, memungkinkan data agar lolos untuk dijadikan data model tipe-tipe proses yang melaksanakan prosedur yang lain, untuk mentransformasikan data ke suatu format yang prosesnya lebih mudah dan efektif untuk kebutuhan pengguna. Data pre-processing yang baik dan memenuhi syarat untuk menemukan data untuk dijadikan model[17].

\section{B. Materi}

Data yang digunakan adalah data primer yang diperoleh dari perusahaan PT. BIMA yang beroperasi di Terminal Nilam Multipurpose Pelabuhan Tanjung Perak Surabaya. Data memiliki periode selama satu tahun. dimulai dari Januari 2019 sampai dengan Desember 2019. Data yang didapat berupa data mentah digital yang dianalisa untuk menentukan variabel yang selanjutnya akan dijadikan obyek penelitian sebagaimana disajikan pada Tabel 1. 


\begin{tabular}{lc} 
Tabel 1. Data Primer & \\
\hline \hline \multicolumn{1}{c}{ Daftar Isi } & Atribut Terpilih? \\
\hline Performance Chart & Tidak \\
Performance Report & Tidak \\
Daily Report & Tidak \\
Hour Meter & Ya \\
Fuel Consumption & Tidak \\
Spare Parts Used & Ya \\
Breakdown Report & Ya \\
Shutdown Report & Ya \\
Accident Report & Tidak \\
Maintenace Report & Tidak \\
\hline
\end{tabular}

Performance Chart merupakan data grafik kinerja selama satu bulan, performance report adalah laporan data kinerja selama satu bulan, daily report adalah laporan harian setiap shift kerja, hour meter adalah data penggunaan container crane selama sehari dengan hitungan jam. Selebihnya, fuel consumption adalah data penggunaan bahan bakar perhari selama satu bulan, spare part used adalah data suku cadang yang digunakan, breakdown adalah data kerusakan, shutdown data kerusakan yang menyebabkan crane berhenti total sehingga tidak dapat beroperasi. Sementara accident report dan maintenance report adalah data kecelakaan pada crane dan laporan perawatan.

Beberapa data yang yang digunakan sesuai kebutuhan penelitian yaitu atribut tanggal terakhir perawatan, hour meter (HM), breakdown (BD), shutdown (SD), dan sparepart (SP). Atribut ini terpilih atas ketersediaan dan keterlengkapan data dari narasumber. Empat variabel terpilih seperti tertera pada Tabel 2.

Tabel 2. Atribut Terpilih

\begin{tabular}{lll}
\hline \multicolumn{1}{c}{ Atribut } & \multicolumn{1}{c}{ Uraian } & \multicolumn{1}{c}{ Tipe Data } \\
\hline$H M$ & Hour Meter & Real (Days) \\
$S D$ & Shutdown & Real (Days) \\
$B D$ & Breakdown & Real (Days) \\
$S P$ & Spare Parts & Real (Days) \\
\hline \hline
\end{tabular}

\section{Modelling}

Tujuan dari modelling diagram di atas ialah berfungsi sebagai sarana perancangan sistem untuk melakukan abstraksi terhadap perangkat lunak berbasis objek. Unified Modeling Language (UML) dapat digunakan untuk mempermudah pengembangan aplikasi yang bersifat berkelanjutan[18].

Diagram model pada penelitian ini, didapatkan mulai dari input data crane berlanjut dengan proses menggunakan metode cluster K-Means dimana data menjadi class berat dan ringan berlajut dengan output durasi perencanaan perawatan crane berupan jam pelaksanaan perawatan kejadian apa yang mengakibatkan crane berhenti melakukan beraktifitas yang nantinya berdampak pada biaya operasional.

\section{Implementasi Aplikasi}

Pengujian aplikasi dari hasil perancangan sistem yang ada untuk mencapai suatu tujuan yang diinginkan, melaksanakan perintah-perintah yang terstruktur dari awal sampai akhir. Pada Gambar 1, implementasi suatu prosedur data, dimulai dari data input data crane dan lanjut dengan proses data dimana data diproses sesuai metode K-Means yang telah di tentukan. Selanjutnya menemukan kelas berat dan ringan, setiap kelas nantinya akan diberikan suatu pembobotan (jam) yang tepat.

Suatu pembobotan durasi perawatan pada container crane yang mengalami kerusakan, acuan berat, sedang penanganan container crane dilihat dari hour meter, break down, shut down, sparepart pada container crane melakukan aktifitas bongkar muat.

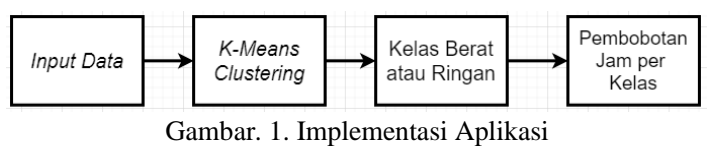

\section{E. Uji Data}

Tabel 3 adalah hasil uji data training $70 \%$ menggunakan cara perhitungan cross-validation untuk menghasilkan skor akurasi nilai generalisasi nilai independen. Teknik ini utamanya digunakan untuk melakukan prediksi model dan memperkirakan seberapa akurat sebuah model prediktif ketika dijalankan, dari sumbu Y (total data), X (variabel), Hasil (Skor) dari perhitungan cross-validation.

\begin{tabular}{ll} 
Tabel 3. Uji Data & \\
\hline \hline \multicolumn{1}{c}{ Variabel } & \multicolumn{1}{c}{ Skor } \\
\hline HM & 0,72846623 \\
BR & 0,48718461 \\
SD & 0,59407362 \\
SP & 0,2189757 \\
BERAT/SEDA & 0,812565 \\
\hline \hline
\end{tabular}

\section{HASIL DAN PEMBAHASAN}

Di halaman login ini, kami menerangkan tampilan utama aplikasi yang dimana user dan password disimpan di dalam tabel database "user". Untuk masuk dalam aplikasi perencanaan perawatan container crane, pengguna harus memasukkan username dan password yang tepat. Fungsi halaman login sendiri secara umum ialah menghindari pihak lain yang tidak mempunyai hak akses.

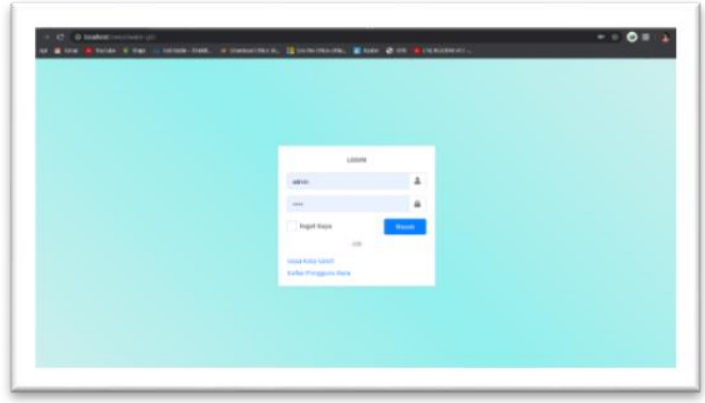

Gambar. 2. Halaman Login 
Halaman Schedule merupakan halaman yang pertama kali di tampilkan setelah melalui proses login. Halaman Schedule menampilkan Chart Bar, dimana Bar 1 merupakan durasi 4 Jam, sedangkan Bar 2 merupakan 2 Jam. Untuk ke 2 durasi tersebut mengacu pada durasi antara lain perawatan, HM, BD, SD dan durasi SP container crane. Chart Bar tersebut bertujuan untuk memberikan informasi jumlah durasi pada setiap bar setiap harinya, contoh: Bar 1 menunjukan jumlah 2 dan Bar 2 menunjukan jumlah 1 pada tanggal 21 Juni 2020, begitu juga seterusnya pada setiap masukan data baru pada setiap data yang akan dieksekusi oleh sistem perencanaan perawatan container crane.

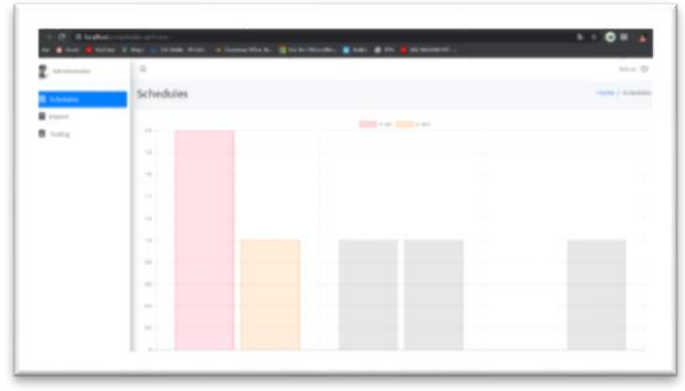

Gambar. 3. Halaman Schedule Grafik

Di halaman Schedule juga menampilkan data dari hasil perhitungan $K$-Means yang telah dilakukan pada menu testing, Di kolom bawah menampilkan tanggal container crane beraktivitas, nama container crane, SP pada sebagian container crane, deskripsi pada setiap container crane, durasi perawatan container crane.

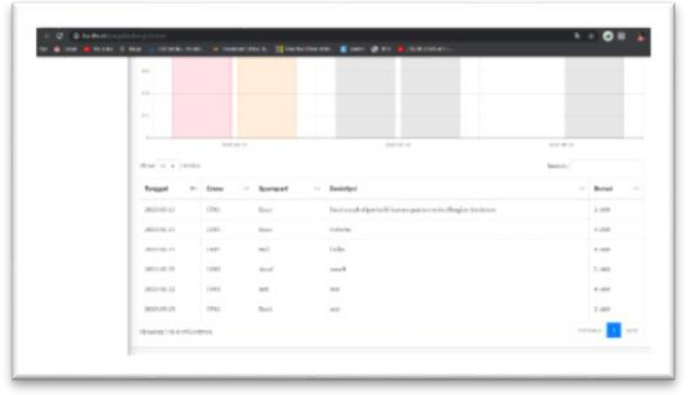

Gambar. 4. Halaman Database Schedule

Halaman Import merupakan halaman yang berfungsi untuk memasukkan dataset yang digunakan untuk training data. Antara lain data tersebut ialah HM, SP, $\mathrm{BR}$, SD, pada setiap container crane. Pada halaman Import terdapat tombol download yang mempermudahkan user atau admin untuk mengambil data, tersedia dalam bentuk *.csv yang digunakan untuk memasukkan data report container crane.

Setelah data diisi sesuai kolom-kolom yang terdapat pada template, maka file tersebut dapat diunggah pada form input. Jika file tersebut berhasil diunggah maka data dari file *.csv akan disimpan ke dalam tabel training pada database dan akan ditampilkan di halaman import dengan bentuk datatable.

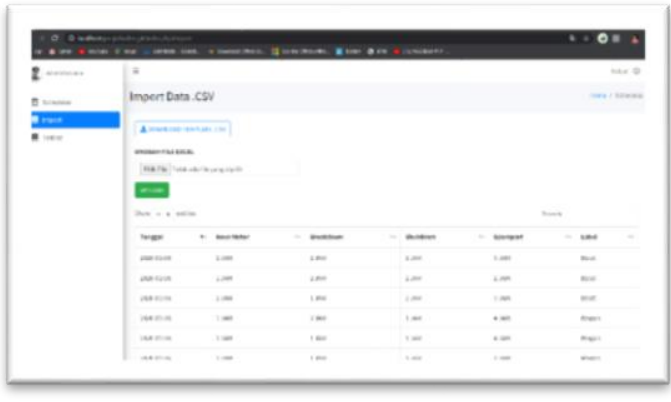

Gambar. 5. Halaman Import

Berikut template yang digunakan untuk diunggah ke Halaman Import, tersedia susunan kolom-kolom yang sudah ditentukan. User perlu mengisikan dataset real sebagai data training yang akan digunakan untuk perhitungan K-Means. Fungsi template ini sendiri adalah mempermudahkan user mengisikan report container crane pada setiap data yang berlabel perlu dilakukan perencanaan perawatan.

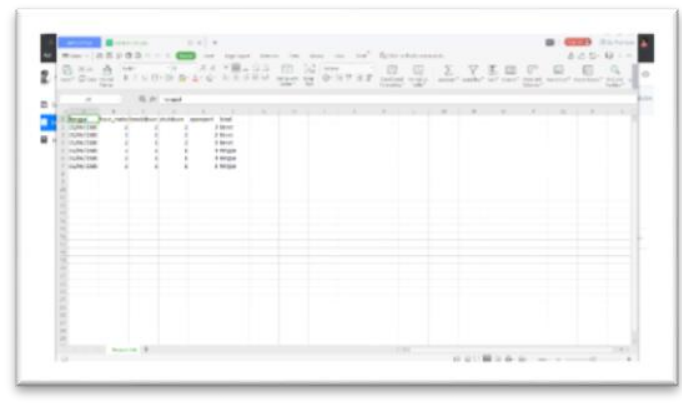

Gambar. 6. Halaman Template

Di halaman Testing, kami menerangkan proses dimana halaman tersebut digunakan untuk melakukan perhitungan algoritma $K$-Means pada setiap data yang masuk, yang sudah melalui perhitungan hasil, serta akan ditampilkan pada halaman schedule. Data testing sendiri bertujuan untuk mengetahui performa algoritma yang sudah dilatih sebelumnya ketika menemukan data yang tidak dikenal/baru.

Terdapat Form Input: Mesin Crane, Tanggal, Nama SP, HM, BD, SD. Bobot SP (Diasumsikan 1 - 10 dari nilai Ringan $k$ Berat). Deskripsi Maintenance (kolom yang digunakan untuk mendeskripsikan kerusakan yang terjadi pada mesin), dimana data yang dimasukkan pada halaman Testing akan menjadi data yang digunakan untuk perhitungan algoritma $K$-Means.

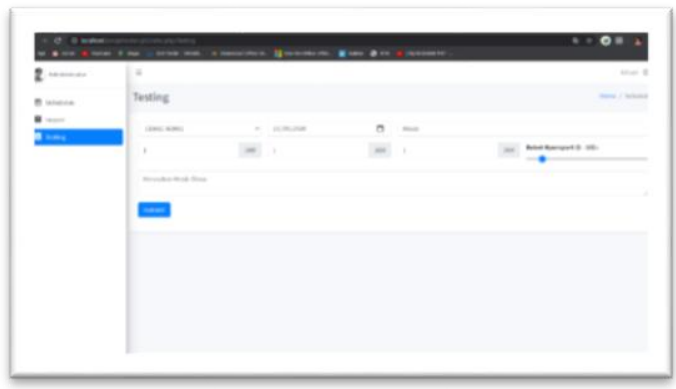

Gambar. 7. Halaman Testing 
Setelah melakukan Submit pada Halaman Testing, maka data akan diproses dan disimpan ke dalam table schedule database. Kemudian, aplikasi akan berpindah ke halaman "Print PDF" yang akan otomatis siap untuk mencetak hasil dari perhitungan dari algoritma.

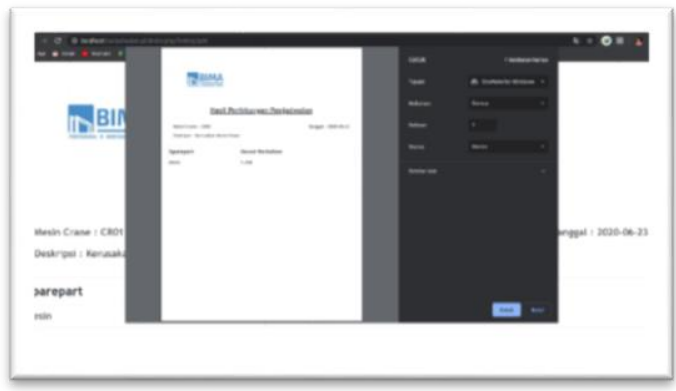

Gambar. 8. Halaman Print PDF

\section{KESIMPULAN}

Pada penelitian ini kami menghasikan sebuah Aplikasi perencanaan perawatan pada container crane yang mengngalami kerusakan berat atau ringan. Bagi kami, penelitian ini sangat menjawab kebutuhan riset dimana data yang telah diterima menghasilkan jawaban penanganan perawatan pada container crane yang sudah lama tidak bisa melakukan perawatan yang tepat, dikarenakan input data report kerusakan secara manual. Input data memiliki rate human error yang cukup tinggi, sehingga perlu diatasi oleh algoritma clustering $K$-Means.Penelitian menunjukkan hasil memuaskan, dikarenakan riset data yang sangat mendalam untuk mendapatkan model pre-processing yang baik untuk mendapatkan class yang dimana dinyatakan berat dan ringan yang menghasikan durasi perawatan yang akurat. Pada penelitian di masa depan, dapat digunakan banyak variabel dan atribut lain yang menjadi tambahan nilai kelas perawatan container crane.

\section{REFERENSI}

[1] L. S. Dalenogare, G. B. Benitez, N. F. Ayala, and A. G. Frank, "The expected contribution of Industry 4.0 technologies for industrial performance," Int. J. Prod. Econ., vol. 204, pp. 383-394, 2018.

[2] W. Zhang, J. Wang, S. Du, H. Ma, W. Zhao, and H. Li, "Energy management strategies for hybrid construction machinery: Evolution, classification, comparison and future trends," Energies, vol. 12, no. 10, p. 2024, 2019.

[3] M. Destiningrum and Q. J. Adrian, "Sistem Informasi Penjadwalan Dokter Berbasis Web Dengan Menggunakan Framework Codeigniter (Studi Kasus: Rumah Sakit Yukum Medical Centre)," J. Teknoinfo, vol. 11, no. 2, pp. 30-37, 2017.

[4] R. Aprianto, W. Wulandari, and N. Hafifah, "Pengembangan Aplikasi Web Mobile Penjadwalan Tugas Aparatur Desa Untuk Meningkatkan Layanan Masyarakat," JTKSI (Jurnal Teknol. Komput. dan Sist. Informasi), vol. 1, no. 3, pp. 81-86, 2018.

[5] N. Novita, M. A. Ganiardi, I. Ariyanti, and D. Khairunnisa, "The Design of The Semester Exam Scheduling Application At The State Polytechnic Of Sriwijaya," in Journal of Physics: Conference Series, 2020, vol. 1500, no. 1, p. 12123.
[9] M. I. Shofyan et al., "Expert System Design for Web-Based Lecturer Scheduling," in Journal of Physics: Conference Series, 2019, vol. 1175, no. 1, p. 12119.

[10] S. Kumar, V. K. Solanki, S. K. Choudhary, A. Selamat, and R. González Crespo, "Comparative Study on Ant Colony Optimization (ACO) and K-Means Clustering Approaches for Jobs Scheduling and Energy Optimization Model in Internet of Things (IoT).," Int. J. Interact. Multimed. $\backslash \&$ Artif. Intell., vol. 6, no. 1, 2020.

[11] G. Muthusamy and S. R. Chandran, "Cluster-based Task Scheduling Using K-Means Clustering for Load Balancing in Cloud Datacenters," J. Internet Technol., vol. 22, no. 1, pp. 121-130, 2021.

[12] J. T. Lin, C.-C. Chiu, E. Huang, and H.-M. Chen, "A multifidelity model approach for simultaneous scheduling of machines and vehicles in flexible manufacturing systems," Asia-Pacific J. Oper. Res., vol. 35, no. 01, p. 1850005, 2018.

[13] Y. Jiang, B. Li, H. Zhang, Q. Luo, and P. Zhou, "A Novel Classification Scheme of Moving Targets at Sea Based on Ward's and K-means Clustering," in Proceedings of the 2nd International Conference on Computer Science and Application Engineering, 2018, pp. 1-5.

[14] X. Liu, Y. Liu, N. Zhang, W. Wu, and A. Liu, "Optimizing trajectory of unmanned aerial vehicles for efficient data acquisition: A matrix completion approach," IEEE Internet Things J., vol. 6, no. 2, pp. 1829-1840, 2019.

[15] S. A. Alasadi and W. S. Bhaya, "Review of data preprocessing techniques in data mining," J. Eng. Appl. Sci., vol. 12, no. 16, pp. 4102-4107, 2017.

[16] B. Yang, X. Fu, N. D. Sidiropoulos, and M. Hong, "Towards k-means-friendly spaces: Simultaneous deep learning and clustering," in international conference on machine learning, 2017, pp. 3861-3870.

[17] S. Symeonidis, D. Effrosynidis, and A. Arampatzis, "A comparative evaluation of pre-processing techniques and their interactions for twitter sentiment analysis," Expert Syst. Appl., vol. 110, pp. 298-310, 2018.

[18] I. M. B. Adnyana, "Perancangan Sistem Penjadwalan Asisten Dosen Menggunakan Algoritma Genetika (Studi Kasus: STIKOM Bali)," E-Proceedings KNSI\&I STIKOM Bali, pp. 569-574, 2017. 